\title{
Receptor-Mediated and Fluid-Phase Transcytosis of Horseradish Peroxidase across Rat Hepatocytes
}

\author{
Isabella Ellinger and Renate Fuchs \\ Department of Pathophysiology, Medical University of Vienna, Währinger Gürtel 18-20, 1090 Vienna, Austria \\ Correspondence should be addressed to Renate Fuchs, renate.fuchs@meduniwien.ac.at
}

Received 3 August 2009; Revised 11 October 2009; Accepted 4 November 2009

Academic Editor: Xue-Ru Wu

Copyright (๑) 2010 I. Ellinger and R. Fuchs. This is an open access article distributed under the Creative Commons Attribution License, which permits unrestricted use, distribution, and reproduction in any medium, provided the original work is properly cited.

\begin{abstract}
Horseradish peroxidase (HRP) is often used as a fluid-phase marker to characterize endocytic and transcytotic processes. Likewise, it has been applied to investigate the mechanisms of biliary secretion of fluid in rat liver hepatocytes. However, HRP contains mannose residues and thus binds to mannose receptors (MRs) on liver cells, including hepatocytes. To study the role of MRmediated endocytosis of HRP transport in hepatocytes, we determined the influence of the oligosaccharid mannan on HRP biliary secretion in the isolated perfused rat liver. A 1-minute pulse of HRP was applied followed by marker-free perfusion. HRP appeared in bile with biphasic kinetics: a first peak at 7 minutes and a second peak at 15 minutes after labeling. Perfusion with $0.8 \mathrm{mg} / \mathrm{mL}$ HRP in the presence of a twofold excess of mannan reduced the first peak by $41 \%$ without effect on the second one. Together with recently published data on MR expression in rat hepatocytes this demonstrates two different mechanisms for HRP transcytosis: a rapid, receptor-mediated transport and a slower fluid-phase transport.
\end{abstract}

\section{Introduction}

The liver plays a major role in the secretion of macromolecules into bile either by receptor-mediated or unspecific fluid-phase transcytosis. Although the liver is composed of parenchymal (hepatocytes) and nonparenchymal cells (endothelial cells, Kupffer cells, Ito cells), only hepatocytes are involved in bile formation and biliary secretion of bloodderived molecules. As isolated hepatocytes in culture do not form a polarized epithelial layer where the apical and basolateral surfaces are accessible at opposite sides, transcytosis studies are confined to in vivo experiments or to the isolated perfused rat liver $[1,2]$. Using the latter system, biliary secretion of various ligands taken up by receptor-mediated and/or fluid-phase endocytosis has been investigated so far. In contrast to other polarized epithelial cells (intestine, kidney, placenta) receptor-mediated endocytic processes are mainly confined to the basolateral (sinusoidal) surface of hepatocytes [1]. One of these sinusoidal receptors is a receptor for galactose-containing glycoproteins, so-called asialoglycoproteins. This galactose receptor or asialoglycoprotein receptor (ASGPR) clears defective asialoglycoproteins (e.g., asialoorosomucoid; ASOR) from the circulation by receptormediated endocytosis. The receptors recycle and ASOR is directed to lysosomes for degradation. However, about 0.5$3 \%$ of internalized ASOR is missorted into the transcytotic route and consequently secreted intact into bile $[3,4]$. Interestingly, the kinetics and amount of biliary secretion of different fluid-phase markers such as inulin or dextrans (MW 2-70 kDa) differ considerably, an effect that is generally attributed to their different molecular weight and/or charge $[5,6]$. Even more surprising, horseradish peroxidase (HRP), following short pulse labeling, has a biphasic appearance in bile: the first, faster peak is assumed to occur by a paracellular route, while the second, slower peak takes place by transcytosis [7]. Transcytosis of the latter peak has been demonstrated by its complete absence in the presence of microtubule depolymerizing drugs [8]. With respect to the fast HRP appearance in bile the following data argue against a paracellular pathway: we have previously shown that low-temperature perfusion $\left(16^{\circ} \mathrm{C}\right)$ results in a delayed appearance of the first peak in bile as compared to perfusion at $37^{\circ} \mathrm{C}$ [9]. Furthermore, 2 minutes after HRP loading HRP containing vesicles were seen in the vicinity of the canalicular 
membrane [7]. Moreover, HRP is not an ideal fluid-phase marker as it is a mannose-containing glycoprotein and thus binds to mannose receptors (MR) on hepatic Kupffer and endothelial cells with high affinity [10-12]. In addition, HRP binds with low affinity ( $\mathrm{Km} \sim 4 \mu \mathrm{M})$ to isolated hepatocytes $[11,13]$ and in these cells HRP uptake up to $0.2 \mathrm{mg} / \mathrm{mL}$ could be competed by mannan, indicative for receptor-mediated endocytosis via an MR. To study the potential role of hepatic MR on HRP biliary secretion we determined the influence of the mannose oligosaccharide mannan $(\mathrm{MW} \sim 100 \mathrm{kD})$ on HRP transport in the isolated perfused rat liver.

\section{Materials and Methods}

2.1. Animals. Male Louvain rats $(250-300 \mathrm{~g})$ were obtained from a local breeding farm and were kept under a controlled lighting schedule with a 12-hour dark period. Animals had free access to food and water but were fasted overnight before the experiment. Before surgical procedures, rats were anesthetized by an intraperitoneal injection of urethane solution ( $1 \mathrm{~mL} / 100 \mathrm{~g}$ body-weight).

2.2. Materials. All chemicals were purchased from Sigma Chem. Co (Vienna, Austria). FITC-dextran $(70 \mathrm{kDa})$ was extensively dialyzed against Tris-buffered saline $(\mathrm{pH}$ 7.34) and finally against phosphate-buffered saline ( $\mathrm{pH}$ 7.4) before use. Asialoorosomucoid (ASOR) was obtained by enzymatic desialylation of $\alpha 1$-acid glycoprotein [14]. ASOR was iodinated in the presence of iodogen (Pierce) to a specific activity of approximately $1,4 \times 10^{6} \mathrm{cpm} / \mu \mathrm{g}$ ASOR.

\subsection{Biliary Secretion of Markers in the Isolated Perfused Rat} Liver. Following surgical removal, isolated rat livers were equilibrated for 30 minutes at $37^{\circ} \mathrm{C}$ by single-pass perfusion with Krebs-Henseleith bicarbonate buffer (KHB; containing $10 \mathrm{mM}$ glucose and $20 \mu \mathrm{M}$ taurocholic acid and gassed with a humidified mixture of $93 \% \mathrm{O}_{2} / 7 \% \mathrm{CO}_{2}, \mathrm{pH} 7.4$ ) at a perfusion rate of $3 \mathrm{~mL} / \mathrm{min}$ and g liver $[15,16]$. Biliary secretion of the respective marker was analyzed by single-pass perfusion at $37^{\circ} \mathrm{C}$. HRP $(0.08 \mathrm{mg} / \mathrm{mL}, 0.8 \mathrm{mg} / \mathrm{mL}$ or $8 \mathrm{mg} / \mathrm{mL} \mathrm{KHB})$ or FITC-dextran $(5 \mathrm{mg} / \mathrm{mL} \mathrm{KHB})$ was perfused through the liver for 1 minute at $37^{\circ} \mathrm{C}$ followed by marker-free perfusion for 40 minutes. Where indicated, a twofold access of mannan over HRP was included in the perfusion buffer. Single bile drops were collected and analyzed for the respective marker concentration. To determine the kinetics of biliary secretion of ${ }^{125} \mathrm{I}$-ASOR at $37^{\circ} \mathrm{C}$, the liver was perfused for 2 minutes with ${ }^{125} \mathrm{I}$-ASOR $\left(1.3-2.3 \times 10^{5} \mathrm{cpm} / \mathrm{mL} \mathrm{KHB}\right)$ followed by marker-free perfusion for 40 minutes. Single bile drops were collected and TCA-precipitable (intact ASOR) and TCAsoluble (degraded ASOR) counts in each bile drop were determined.

2.4. Marker Determination. FITC-fluorescence of FITCdextran per biledrop was measured in a spectrofluorometer (FP-777, Jasco, Japan) using $495 \mathrm{~nm}$ and $515 \mathrm{~nm}$ as excitation and emission wavelengths, respectively. After subtraction of background fluorescence, values were converted to concentration (pg FITC-dextran/biledrop) with the help of a calibration curve. The enzymatic activity of HRP per bile drop was determined based on standard curve according to Marsh et al. [17]. Following perfusion with ${ }^{125}$ I-ASOR single bile drops were subjected to precipitation with $10 \%$ TCA (final concentration) and after centrifugation $(1500 \times \mathrm{g}$, 15 minutes) radioactivity in the supernatant (TCA soluble degradation products) and pellet (TCA precipitable, i.e., intact ${ }^{125} \mathrm{I}$-ASOR) were determined by $\gamma$-counting (1282Compugamma CS, LKB).

2.5. Calculations. The bile flow was calculated by determining the time when each bile drop was formed normalized to $1 \mathrm{~g}$ liver (bile flow in $\mu \mathrm{L} / \mathrm{min}$ and g liver). The amount of marker/bile drop was determined using the respective calibration curve (HRP, FITC-dextran) or radioactivity. As one bile drop corresponds to $8 \mu \mathrm{L}$ bile, these data were converted to marker secretion (amount of marker/min and $g$ liver) by division by 8 and multiplication with the respective bile flow. The appearance of the marker in bile was corrected for the dead space of the bile duct cannula. The cummulative HRP secretion was obtained by summing up the amount of HRP/bile drop over time. To analyze differences between the first and the second peak of HRP secretion, we defined the cumulative amount that was secreted between 0 and 10 minutes to correspond to the 1st HRP peak (secretion maximum 6-8 minutes). This amount was then subtracted from the total amount of HRP secreted within 40 minutes to obtain the total amount secreted during the 2nd HRP peak (secretion maximum 15 minutes).

\section{Results}

3.1. Kinetics of Biliary Secretion of the Fluid-Phase Marker FITC-Dextran and the Ligand, Asialoorosomucoid (ASOR). For comparison, the secretion kinetics of a bona fide fluidphase marker, FITC-dextran, and a galactose-terminated ligand, asialoorosomuciod (ASOR), were analyzed. FITCdextran (MW $70 \mathrm{kDa} ; 5 \mathrm{mg} / \mathrm{mL}$ ) was added to the perfusate and perfused through the liver for 1 minute (= pulse) under single-pass conditions. To maintain constant bile flow $20 \mu \mathrm{M}$ taurocholic acid was always included in the perfusion buffer. Perfusion was then continued in the absence of marker for up to 40 minutes. The concentration of the marker was analyzed in single bile drops and data were related to bile flow and normalized to $1 \mathrm{~g}$ liver. As shown in Figure 1(a), FITCdextran appeared in bile 4 minutes after marker addition to the perfusate. The secretion rate increased with time reaching a peak at 8 minutes and then dropped to 0 at 40 minutes. The bile flow (Figure 1(b)) revealed a transient decrease and subsequent increase when the perfusion medium was changed but then remained constant at about $1.75 \mu \mathrm{L} / \mathrm{min}$ and $g$ liver throughout the perfusion indicative for sufficient oxygen supply, ATP generation, and intact liver function [16].

${ }^{125}$ I-ASOR was used as high affinity ligand for the ASGPR. ASOR is rapidly and efficiently taken up from 


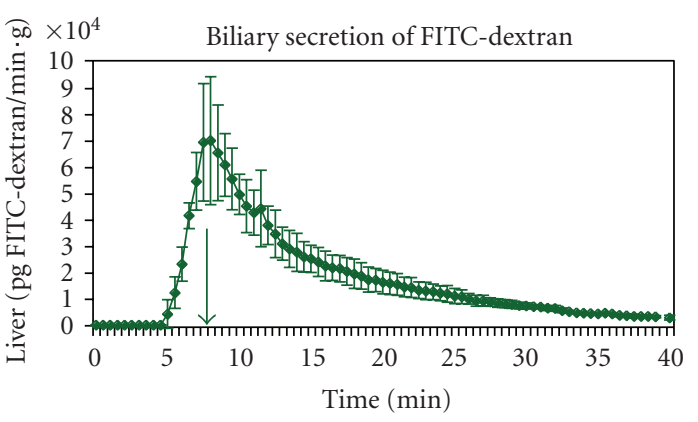

(a)

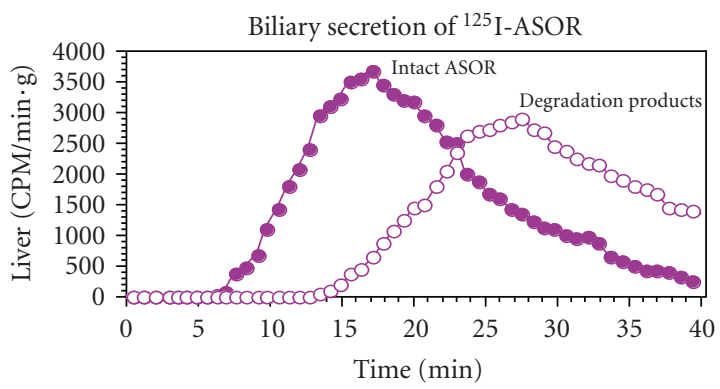

(c)

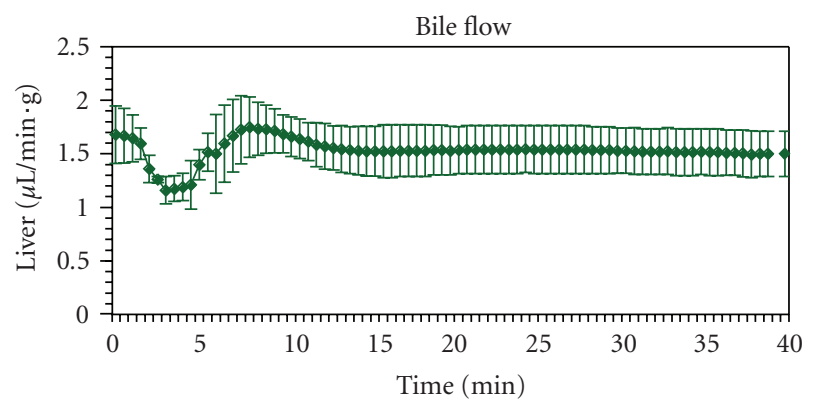

(b)

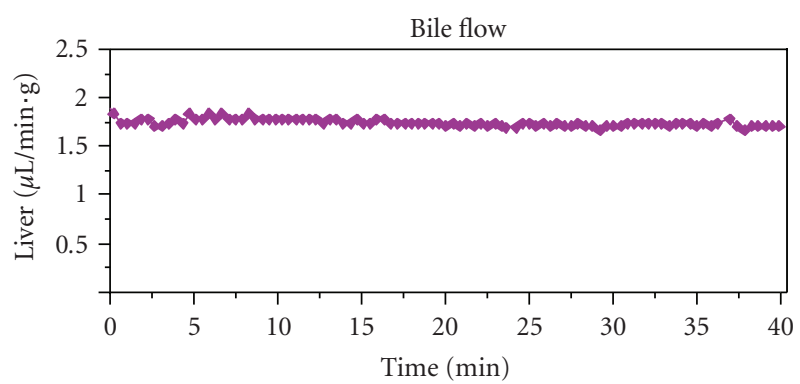

(d)

FIGURE 1: Kinetics of biliary secretion of FITC-dextran (a) and ASOR (c). Livers were isolated and following 30-minute perfusion, FITCdextran $(5 \mathrm{mg} / \mathrm{mL})$ or ${ }^{125} \mathrm{I}$-ASOR was administered in the perfusion medium (KHB) for 1 minute and 2 minutes, respectively, at $37^{\circ} \mathrm{C}($ time 0) followed by a single-pass perfusion with marker-free $\mathrm{KHB}$ at $37^{\circ} \mathrm{C}$. (a) Single bile drops were collected and the FITC-dextran concentration was determined using a calibration curve. Data were converted into secretion (ng FITC-dextran/min and g liver). In (b) the corresponding bile flow is shown (mean \pm SD from two ( $a, b)$ perfusions). (c) Single bile drop were subjected to precipitation with $10 \%$ TCA. Secretion of intact ASOR (TCA precipitable counts) and degradation products (TCA soluble counts) of one typical experiment out of six are shown. (d) Corresponding bile flow.

the perfusate and after ligand-receptor dissociation in early endosomes the receptor is recycled and ASOR is sorted to lysosomes [18, 19]. The appearance of ASOR degradation products in bile reflects the kinetics of arrival in lysosomes. About $90 \%$ of ASOR degradation products are released into the perfusate and the remainder into bile [3]. Since $0.5 \%-3 \%$ of internalized ASOR is missorted and secreted intact into bile, determination of TCA-precipitable and TCAsoluble radioactivity in bile correlates with transcytosis and transport to lysosomes, respectively $[3,4]$. Biliary secretion of ASOR at $37^{\circ} \mathrm{C}$ was analyzed following a 2-minute pulse of ${ }^{125} \mathrm{I}$-ASOR with subsequent marker-free perfusion of the liver. Single bile drops were collected and TCA-precipitable (intact) and TCA-soluble (degraded) radioactivity therein were determined (Figure 1(c)). Intact ${ }^{125}$ I-ASOR appeared in bile within 6 minutes after the pulse, while maximum biliary secretion was found about 17 minutes after uptake. 15 minutes after internalization TCA-soluble counts appeared in bile, corresponding to ASOR arrival in lysosomes, immediate degradation and release of degradation products into the perfusate (not shown; $[3,4]$ ) and bile. The bile flow (Figure $1(\mathrm{~d})$ ) remained constant at $1.8 \mu \mathrm{L} / \mathrm{g}$ liver and min throughout this perfusion. Taken together, biliary secretion of the fluid-phase marker FITC-dextran is faster than the ligand ASOR.
3.2. Kinetics of Biliary Secretion of HRP and the Effect of Mannan on HRP Secretion. HRP $(0.8 \mathrm{mg} / \mathrm{mL} \mathrm{KHB})$ was added to the perfusion medium for 1 minute followed by markerfree perfusion (Figure 2(a)). Although HRP appeared in bile roughly at the same time as FITC-dextran, the secretion rate revealed two peaks at 7 minutes and 15 minutes, respectively. These two peaks were seen irrespective of the HRP concentration perfused through the liver $(0.08 ; 0.8$; $8 \mathrm{mg} / \mathrm{mL}$ ) and are in agreement with data from different laboratories $[7,8,20,21]$. The bile flow, shown in Figure 2(b), remained constant at $1.6 \mu \mathrm{L} / \mathrm{g}$ liver and min throughout this perfusion. The cumulative secretion is shown in Figure 2(c). Comparison of HRP secretion with secretion of FITCdextran and ASOR revealed that HRP exhibits a similar kinetics as the fluid-phase marker (1st HRP peak) as well as that of the ligand (2nd HRP peak).

Next, we analyzed the influence of $1.6 \mathrm{mg} / \mathrm{mL}$ mannan on HRP secretion (Figure 3 ). Similar to the absence of mannan (compare to Figure 2) two peaks of secreted HRP were seen, at about 8 minutes and 16 minutes, respectively (Figure $3(\mathrm{a})$ ). The bile flow was maintained at about $1.5 \mu \mathrm{L} / \mathrm{min}$ and g liver (Figure 3(b)). Figure 3(c) demonstrates that the total cumulative secretion was reduced in the presence of mannan as compared to its absence (compare to Figure 2(c)). To differentiate whether mannan 


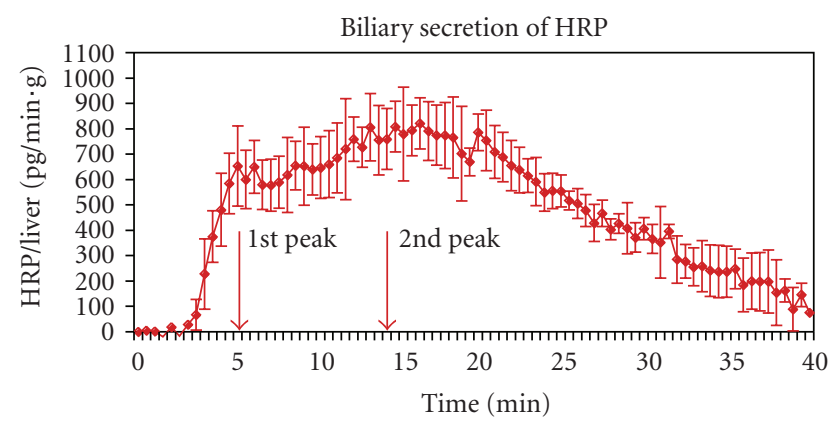

(a)

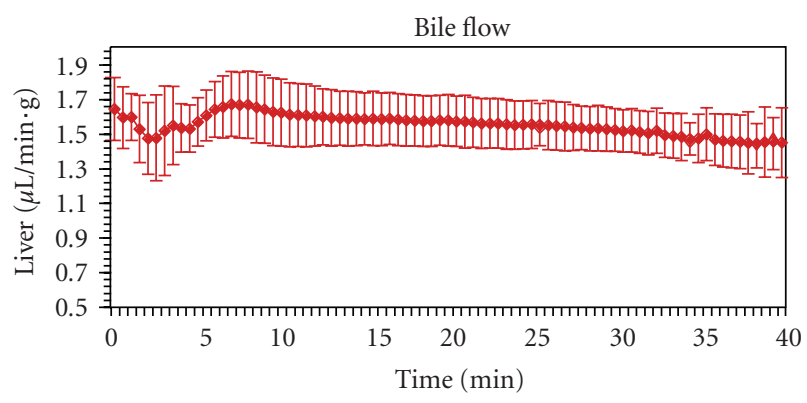

(b)

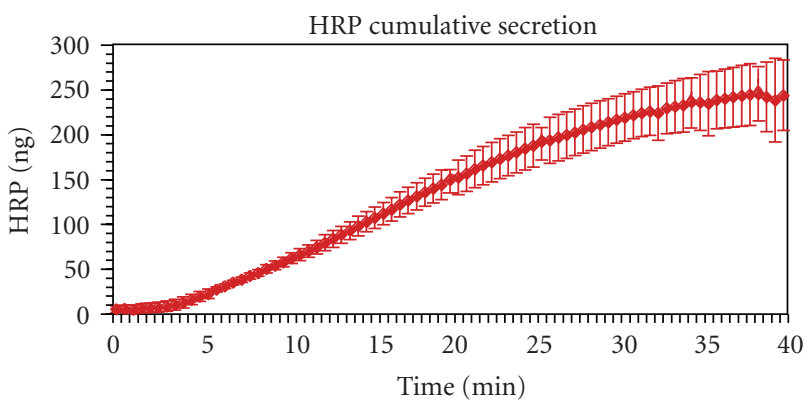

(c)

FIgURE 2: Kinetics of biliary secretion of HRP in the absence of mannan in the perfused rat liver. Isolated livers were perfused with $\operatorname{HRP}(0,8 \mathrm{mg} / \mathrm{mL})$ for 1 minute at $37^{\circ} \mathrm{C}$ (time 0$)$ followed by a single pass perfusion with marker-free $\mathrm{KHB}$ at $37^{\circ} \mathrm{C}$. The amount of HRP in single bile drops was determined and the secretion rate was calculated (a) based on the bile flow (b). Data shown are the mean \pm SD five perfusions. (c) The total amount of HRP (cummulative HRP secretion) secreted into bile as a function of the perfusion time is shown.

influenced rather the first or the second peak, the amount of HRP being secreted between 0 and 10 minutes (i.e., during the fast, first peak) and between 10 minutes and 40 minutes (i.e., during the slow, second peak) was analyzed. As depicted in Figure 4, the first HRP peak was reduced by $41 \%$ by mannan without any influence on the second peak. When HRP at $0.08 \mathrm{mg} / \mathrm{mL}$ was applied in the perfusate, the first peak was also decreased by mannan by $32 \%$ while the second peak was slightly increased by $14 \%$ (data not shown). However, due to the low HRP concentration in single bile drops individual experiments varied considerable. When the HRP concentration in the perfusate was raised to $8 \mathrm{mg} / \mathrm{mL}$, no significant effect of $16 \mathrm{mg} / \mathrm{mL}$ mannan could be

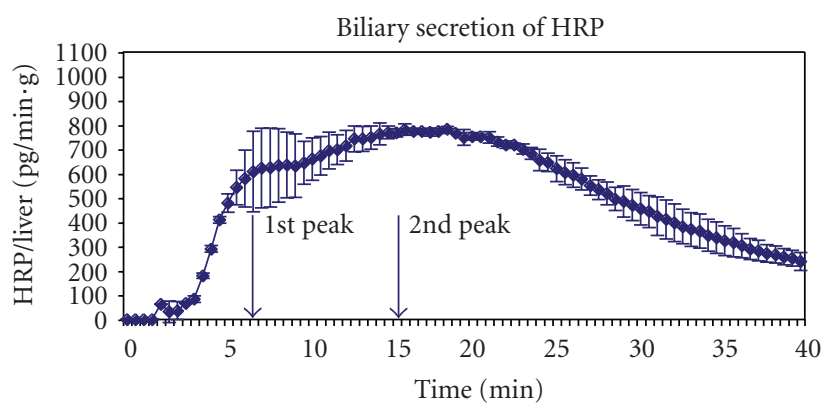

(a)

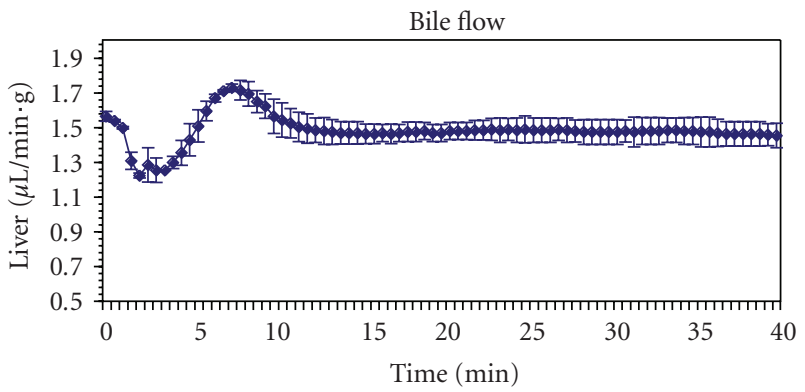

(b)

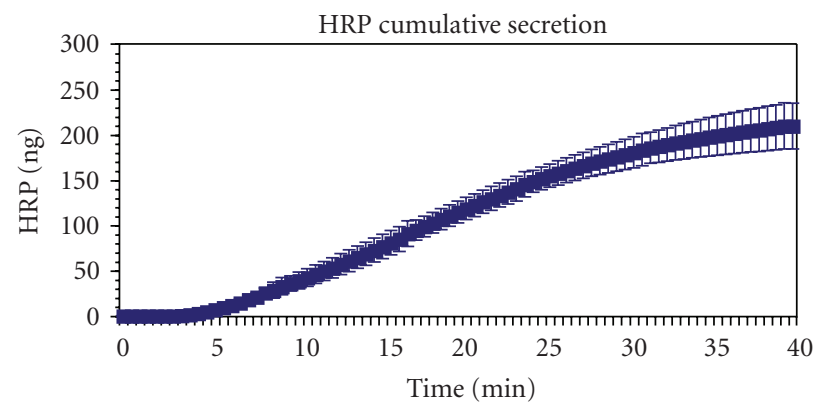

(c)

FIGURE 3: Effect of mannan on biliary HRP secretion. Livers were isolated and following 30 minutes perfusion, $\operatorname{HRP}(0,8 \mathrm{mg} / \mathrm{mL})$ plus $1.6 \mathrm{mg} / \mathrm{mL}$ mannan was administered in the perfusion medium (KHB) for 1 minute at $37^{\circ} \mathrm{C}$ (time 0 ) followed by single-pass perfusion with marker-free $\mathrm{KHB}$ at $37^{\circ} \mathrm{C}$ for 40 minutes. The amount of HRP in single bile drops was determined and the secretion rate was calculated (a) based on the bile flow (b). Data shown are the mean \pm SD of four perfusions. (c) The total amount of HRP (cummulative HRP secretion) secreted into bile as a function of the perfusion time is shown.

seen (data not shown). These data demonstrate that the fast pathway of HRP entry into bile has to occur at least in part by a receptor-mediated transcellular route. Nevertheless, the kinetics of this route clearly differs from that of the ligand ASOR (see Figure 1(c)).

\section{Discussion}

4.1. Characteristics of Liver MR. In our study, we have observed an effect of mannan on the first peak of HRPsecretion that indicates an interaction of HRP with MR on hepatocytes. The MR (180 kDa) was first isolated from 


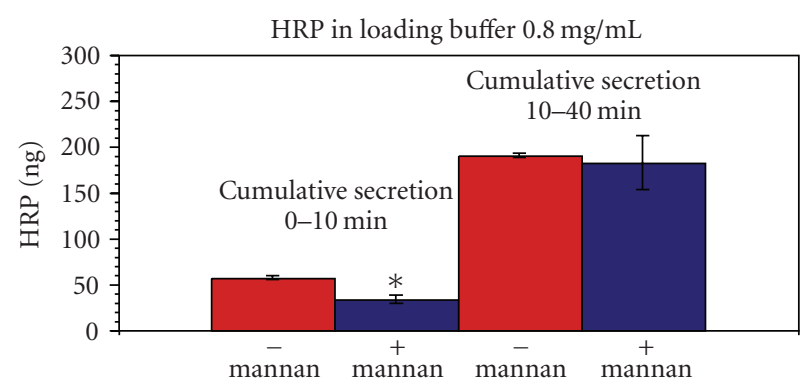

Figure 4: Effect of mannan on cumulative HRP secretion. The cumulative secretion from the experiments shown in Figure 2 (absence of mannan) and Figure 3 (presence of mannan) was calculated for 0-10 minutes ( 1 st peak) and 10-40 minutes ( 2 nd peak). Data shown are the mean \pm SEM from five and four perfusions, respectively. Note that only the first peak ( $0-10$ minutes) was reduced in the presence of mannan. Asterisk indicates significant differences at $P \leq .05$.

rat liver Kupffer cells [22] and binds glycoproteins with, for example, terminal mannose or fucose groups in a Cadependent manner. The MR is found on monocyte-derived and tissue macrophages, cultured dendritic cells, on hepatic sinusoidal and lymphatic endothelial cells in the small intestine [23]. Its main function is the clearance of many serum glycoproteins, lysosomal enzymes, and denatured collagen containing the respective sugar moieties resulting in their rapid degradation [24-28]. Rat liver endothelial cells exhibit a high MR surface density and high affinity (Km about 30-60 nM) for ligands such as ovalbumin [28] or $\mathrm{N}$-acetylglucosamine containing glycoproteins [29]. MRs are taken up by clathrin-mediated endocytosis due to a conserved lysine residue and a dihydrophobic motif in their short cytoplasmic tail [30, 31]. Internalized MRligand complexes dissociate in the low $\mathrm{pH}$ environment of endosomes [32] resulting in receptor recycling and ligand transport to and degradation in lysosomes $[28,30]$.

Apart from being localized to Kuppfer and endothelial cells receptors for mannose containing glycoproteins were also described in liver parenchymal cells [11,33]. Quantitative data from electron microscopy autoradiographic studies revealed that a minor fraction of mannose-terminated RNase was found in hepatocytes [34]. Similarly, aglycerase was taken up by hepatocytes in a mannose-dependent fashion [35]. Using mannosylated gold particles, Kempka and KolbBachofen demonstrated binding of the marker in coated pits followed by uptake, transcytosis, and secretion into bile by rat hepatocytes in situ [12]. Although these events in hepatocytes were rare as compared to liver sinudoidal cells, they were not completely absent. Using isolated liver parenchymal cells, binding, uptake, and intracellular routing to lysosomes of invertase was shown that could be blocked by mannose [36]. Collectively, these data support the presence of an MR on the sinusoidal surface of rat hepatocytes. However, the MR on hepatocytes is clearly distinct from the MR on Kupffer and endothelial cells and has not been identified, so far. Antibodies specific for the $180 \mathrm{kDa}$ MR on endothelial cells did not reveal a protein with similar molecular weight in hepatocytes [37]. Binding of HRP to isolated hepatocytes at $4{ }^{\circ} \mathrm{C}$ was of low affinity thus preventing the identification of a specific plasma membrane protein [13]. However, HRP uptake at $37^{\circ} \mathrm{C}$ was saturable with a $\mathrm{Km}$ of $8.3 \mathrm{mg} / \mathrm{L}$ and could be inhibited by mannan with an apparent $\mathrm{Ki}$ of $2.5 \mathrm{mg} / \mathrm{L}$ [13] clearly demonstrating the involvement of MR in HRP endocytosis in hepatocytes.

\subsection{Endocytic Compartments Involved in Receptor-Mediated} and Fluid-Phase Transcytosis. Receptor-mediated endocytosis can take place via clathrin-coated pits and vesicles (e.g., ASOR, polymeric IgA), via caveolae (e.g., albumin in endothelial cells), and other less characterized mechanisms $[38,39]$. The prevalence of the respective uptake mechanism depends on the ligand and cell type. Irrespective of the uptake mechanism by which each endocytic vesicle is formed, it contains extracellular fluid and extracellular material (proteins, ions, etc.). Consequently, fluid-phase endocytosis occurs concomitantly with receptor-mediated endocytosis. However, the contribution of distinct endocytosis mechanisms to fluid-phase uptake depends on the cell type under investigation. The kinetics of transfer of different markers, be they ligands or fluid-phase markers, do not necessarily allow a prediction of their intracellular route. FITC-dextran (fluid phase marker) and ASOR (ligand) utilize the same endocytic subcompartments on their transcellular route from the sinusoidal to the canalicular plasma membrane [40]. This has been shown by low-temperature $\left(16^{\circ} \mathrm{C}\right)$ perfusion of isolated perfused rat livers and by subcellular liver fractionation [40]. Under this condition FITC-dextran and ASOR accumulate in early endosomes resulting in inhibition of transcytosis of both molecules and inhibition of lysosomal degradation of ASOR. Nevertheless, they are secreted into bile with completely different kinetics (Figures 1(a) and 1(c)).

Similar to the transcytosis of ASOR and FITC-dextran, low-temperature perfusion blocks the slow pathway of HRP secretion indicative for involvement of the same endocytic compartments (early endosomes) during transport to the canalicular membrane. Consequently, a part of HRP has to be taken up into typical early endosomes (that accumulate marker at $16^{\circ} \mathrm{C}$ ), is then directed into transcytotic vesicles, and appears in bile at about 15 minutes (Figure 5). In contrast, a proportion of HRP is internalized via an MR (mannan competeable uptake) into endocytic compartments distinct from ASOR-containing endosomes. Such a distinct fast transcellular pathway is supported by the observation that HRP appearance in bile during $16^{\circ} \mathrm{C}$ perfusion is only delayed but not blocked [9] and that HRP-containing endosomes are observed within 2 minutes in the vicinity of the canalicular membrane [7]. Evidence for distinct internalization pathways has also been obtained for other biliary secreted markers. Albumin and ASOR have been localized in distinct endocytic compartments early after uptake in isolated hepatocytes at low temperature [41].

It is still a matter of debate whether the fast HRP appearance in bile is (additionally) due to paracellular transport as supported by stimulation of this peak under 


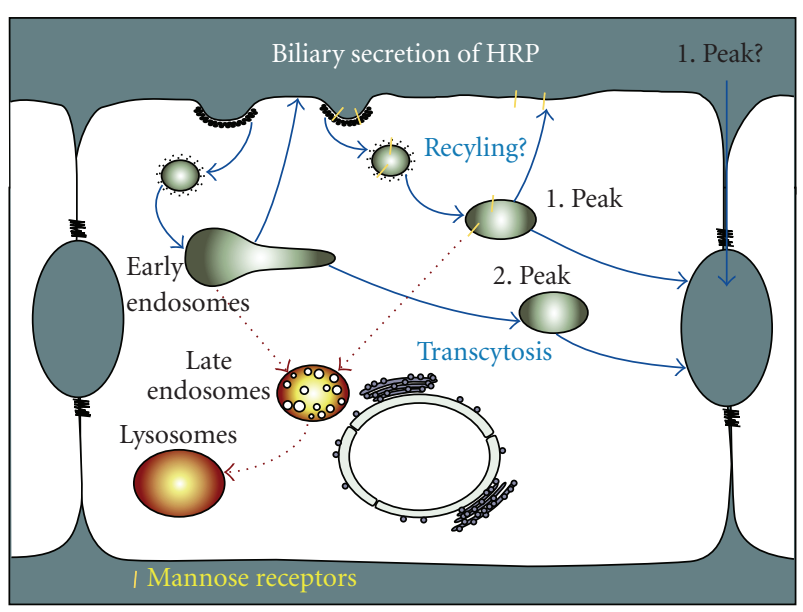

FIGURE 5: Scheme of potential pathways involved in HRP secretion into bile. Compartments labeled by HRP are indicated by blue color. Although HRP is also directed to lysosomes, only those endosomes involved in transcytosis are shown in blue. MRs (yellow bars) presumably recycle back to the sinusoidal plasma membrane.

postcholestatic conditions and by reagents that lead to intrahepatic cholestasis $[8,9,42]$. All these treatments increase the permeability of the tight junctions and could therefore explain the stimulatory effect on the first HRP peak [42, 43]. However, the data presented in this investigation clearly demonstrate that a least part of the first HRP peak is reduced by mannan and is thus accounted for by receptor-mediated transcytosis. It may be speculated that mannan reduces the paracellular permeability. However, since mannose receptors are only involved in the binding and subsequent endocytosis of mannose containing glycoproteins to/into cells, it can be assumed that mannan has no influence on the paracellular permeability, though this has not been proven. We cannot think of an experimental setup to unequivocally differentiate between the proportion of the transcellular and paracellular part of the 1st peak. Such a setup is required to determine the effect of mannan treatment on the paracellular permeability.

4.3. Actual HRP Concentration in the Perfusate. Kuppfer cells and endothelial cells have an up to 10-times higher endocytic activity of fluid-phase marker uptake per se [34, $35,44]$ and, in addition, mannose-containing glycoproteins are internalized by high affinity MR into endothelial cells at a very fast endocytic rate $[28,45]$. Consequently, the actual HRP concentration that will be in contact with hepatocytes in the isolated perfused rat liver is unknown. It can be assumed to be much lower as the amount of HRP added to the perfusion buffer due HRP removal by endothelial and Kupffer cells. This may explain the discrepancies between our results and data by Yamaguchi et al. [13]. These authors observed saturation of HRP uptake in isolated hepatocytes already at $0.2 \mathrm{mg} / \mathrm{mL} \mathrm{HRP.}$ In contrast, we could demonstrate mannan inhibitable HRP secretion at $0.8 \mathrm{mg} / \mathrm{mL}$. Thus, when HRP is applied at concentrations ranging between $1 \mathrm{mg} / \mathrm{mL}$ and $10 \mathrm{mg} / \mathrm{mL}$ as in morphological and perfusion studies $[7,8,20,21$,
46] the proportion due to receptor-mediated endocytosis cannot be ignored, although at such HRP concentrations uptake by isolated hepatocytes is mainly by a fluid-phase mechanism.

4.4. Role of Hepatocytes and the Biliary Epithelium in Bile Formation and Composition. Bile is produced by hepatocytes at their canalicular surface due to activity of many solute transporters [47]. The main bile constituent is water (about $96 \%)$. The remainder is composed of bile acids (67\%), phospholipids (22\%), cholesterol (5\%), and proteins (5\%). The canalicular bile then passes through the bile ducts and is collected in the gallbladder for regulated secretion into the intestinal tract [48]. Ductular epithelial cells modify the canalicular bile by a series of secretory and reabsorptive processes resulting in its alkalinization and concentration. Thus, ductular/gallbladder bile has a lower water content (about 87\%) and a higher concentration of all the constituents listed above as canalicular bile. Many biliary proteins (polymeric IgA) are secreted via receptormediated transcytosis while others (albumin, IgG) reach bile by a fluid-phase mechanism. Though it has been shown that the total protein concentration is higher in ductular/gallbladder than in canalicular bile due to water absorption, additional absorptive/secretory processes may affect the concentration of individual proteins [49]. With respect to HRP we may speculate that this marker is endocytosed by ductular cells by a fluid-phase mechanism as shown in isolated rat bile duct epithelial cells $[50,51]$. Such processes may result in a reduction of the amount of HRP in ductular bile. Thus, the actual amount of HRP secreted by hepatocytes may be higher. How ductular endocytosis may affect the concentration of the first and second HRP peak is unknown and cannot be taken into consideration. In any case, we here demonstrate that HRP secretion in the isolated perfused rat liver can be inhibited by mannan indicative for the involvement of MR in HRP uptake by hepatocytes.

\section{Conclusions}

The potential pathways for HRP secretion into bile are summarized in Figure 5: (1) a receptor-mediated, fast, transcellular route, (2) a slow, fluid-phase transcytotic route and (3) most likely also a fast paracellular route that is increased by intra- and extrahepatic cholestasis. Based on previous data $[8,52]$ the slow pathway is identical to that taken by polymeric IgA and ASOR, that is, clathrinmediated uptake into early endosomes where sorting into transcytotic vesicles takes place followed by biliary secretion. This pathway is blocked by $16^{\circ} \mathrm{C}$ in early endosomes and is entirely dependent on microtubules $[8,9,52]$. In contrast, the fast transcellular route is microtubule-independent and insensitive to inhibition by low temperature $[8,9]$. This pathway may involve clathrin-coated pits and vesicles similar to the uptake of mannose containing glycoproteins in dendritic cells [53]. 


\section{Abbreviations}

HRP: Horseradish peroxidase

ASGPR: Asialoglycoprotein receptor

ASOR: Asialoorosomucoid

KHB: Krebs-Henseleith bicarbonate buffer

MR: Mannose receptors.

\section{Acknowledgments}

The authors thank Peter Wyskowsky for perfusion of the isolated rat livers. This work was supported by a grant of the Austrian Science Foundation to RF.

\section{References}

[1] P. L. Tuma and A. L. Hubbard, "Transcytosis: crossing cellular barriers," Physiological Reviews, vol. 83, no. 3, pp. 871-932, 2003.

[2] W. A. Dunn, D. A. Wall, and A. L. Hubbard, "Use of isolated, perfused liver in studies of receptor-mediated endocytosis," Methods in Enzymology, vol. 98, pp. 225-241, 1983.

[3] T. M. Kloppel, "Effects of temperature on the degradation and biliary secretion of asialoorosomucoid by the perfused rat liver: evidence for two intracellular pathways," Journal of Cellular Physiology, vol. 138, no. 3, pp. 555-560, 1989.

[4] T. M. Kloppel, W. R. Brown, and J. Reichen, "Effects of monensin on vesicular transport pathways in the perfused rat liver," Journal of Cellular Biochemistry, vol. 32, no. 3, pp. 235245, 1986.

[5] J. R. Lake, V. Licko, R. W. Van Dyke, and B. F. Scharschmidt, "Biliary secretion of fluid-phase markers by the isolated perfused rat liver. Role of transcellular vesicular transport," The Journal of Clinical Investigation, vol. 76, no. 2, pp. 676684, 1985.

[6] W. G. M. Hardison, P. J. Lowe, and M. Shanahan, "Effect of molecular charge on para- and transcellular access of horseradish peroxidase into rat bile," Hepatology, vol. 9, no. 6, pp. 866-871, 1989.

[7] T. Hayakawa, O. Cheng, A. Ma, and J. L. Boyer, "Taurocholate stimulates transcytotic vesicular pathways labeled by horseradish peroxidase in the isolated perfused rat liver," Gastroenterology, vol. 99, no. 1, pp. 216-228, 1990.

[8] P. J. Lowe, K. S. Kan, S. G. Barnwell, R. K. Sharma, and R. Coleman, "Transcytosis and paracellular movements of horseradish peroxidase across liver parenchymal tissue from blood to bile. Effects of $\alpha$-naphthylisothiocyanate and colchicine," Biochemical Journal, vol. 229, no. 2, pp. 529-537, 1985.

[9] I. Ellinger and R. Fuchs, "Biliary secretion of fluid phase markers is modified under post-cholestatic conditions," Wiener Medizinische Wochenschrift, vol. 158, no. 19-20, pp. 579-582, 2008.

[10] E. Stang, G. M. Kindberg, T. Berg, and N. Roos, "Endocytosis mediated by the mannose receptor in liver endothelial cells. An immunocytochemical study," European Journal of Cell Biology, vol. 52, no. 1, pp. 67-76, 1990.

[11] H. Tolleshaug, T. Berg, and R. Blomhoff, "Uptake of mannoseterminated glycoproteins in isolated rat liver cells. Evidence for receptor-mediated endocytosis in hepatocytes," Biochemical Journal, vol. 223, no. 1, pp. 151-160, 1984.
[12] G. Kempka and V. Kolb-Bachofen, "Binding, uptake, and transcytosis of ligands for mannose-specific receptors in rat liver: an electron microscopic study," Experimental Cell Research, vol. 176, no. 1, pp. 38-48, 1988.

[13] Y. Yamaguchi, E. Dalle-Molle, and W. G. M. Hardison, "Hepatocyte horseradish peroxidase uptake is saturable and inhibited by mannose-terminal glycoproteins," American Journal of Physiology, vol. 264, no. 5, pp. G880-G885, 1993.

[14] W. A. Dunn, J. H. LaBadie, and N. N. Aronson Jr., "Inhibition of 125I-asialofetuin catabolism by leupeptin in the perfused rat liver and in vivo," Journal of Biological Chemistry, vol. 254, no. 10, pp. 4191-4196, 1979.

[15] J. Graf, "Canalicular bile salt-independent bile formation: concepts and clues from electrolyte transport in rat liver," American Journal of Physiology, vol. 244, no. 3, pp. G233G246, 1983.

[16] M. Bessems, N. A. 't Hart, R. Tolba, et al., "The isolated perfused rat liver: standardization of a time-honoured model," Laboratory Animals, vol. 40, no. 3, pp. 236-246, 2006.

[17] M. Marsh, S. Schmid, H. Kern, et al., "Rapid analytical and preparative isolation of functional endosomes by free flow electrophoresis," The Journal of Cell Biology, vol. 104, no. 4, pp. 875-886, 1987.

[18] D. A. Wall, G. Wilson, and A. L. Hubbard, "The galactosespecific recognition system of mammalian liver: the route of ligand internalization in rat hepatocytes," Cell, vol. 21, no. 1, pp. 79-93, 1980.

[19] D. A. Wall and A. L. Hubbard, "Galactose-specific recognition system of mammalian liver: receptor distribution on the hepatocyte cell surface," The Journal of Cell Biology, vol. 90, no. 3, pp. 687-696, 1981.

[20] L. Lora, E. Mazzon, D. Billington, C. Milanesi, R. Naccarato, and D. Martines, "Effects of cyclosporin A on paracellular and transcellular transport of horseradish peroxidase in perfused rat livers," Digestive Diseases and Sciences, vol. 42, no. 3, pp. 514-521, 1997.

[21] D. Alvaro, A. Benedetti, A. Gigliozzi, et al., "Effect of Brefeldin A on transcytotic vesicular pathway and bile secretion: a study on the isolated perfused rat liver and isolated rat hepatocyte couplets," Hepatology, vol. 21, no. 2, pp. 450-459, 1995.

[22] S. A. Linehan, L. Martinez-Pomares, P. D. Stahl, and S. Gordon, "Mannose receptor and its putative ligands in normal murine lymphoid and nonlymphoid organs: in situ expression of mannose receptor by selected macrophages, endothelial cells, perivascular microglia, and mesangial cells, but not dendritic cells," Journal of Experimental Medicine, vol. 189, no. 12, pp. 1961-1972, 1999.

[23] K. Takahashi, M. J. Donovan, R. A. Rogers, and R. A. B. Ezekowitz, "Distribution of murine mannose receptor expression from early embryogenesis through to adulthood," Cell and Tissue Research, vol. 292, no. 2, pp. 311-323, 1998.

[24] P. Opanasopit, K. Shirashi, M. Nishikawa, F. Yamashita, Y. Takakura, and M. Hashida, "In vivo recognition of mannosylated proteins by hepatic mannose receptors and mannanbinding protein," American Journal of Physiology, vol. 280, no. 5, pp. G879-G889, 2001.

[25] I. Malovic, K. K. Sorensen, K. H. Elvevold, et al., "The mannose receptor on murine liver sinusoidal endothelial cells is the main denatured collagen clearance receptor," Hepatology, vol. 45, no. 6, pp. 1454-1461, 2007.

[26] S. J. Lee, S. Evers, D. Roeder, et al., "Mannose receptormediated regulation of serum glycoprotein homeostasis," Science, vol. 295, no. 5561, pp. 1898-1901, 2002. 
[27] D. Fiete, M. C. Beranek, and J. U. Baenziger, "The macrophage/endothelial cell mannose receptor cDNA encodes a protein that binds oligosaccharides terminating with $\mathrm{SO}_{4}-4$ GalNAc $\beta 1,4$ GIcNAc $\beta$ or Man at independent sites," Proceedings of the National Academy of Sciences of the United States of America, vol. 94, no. 21, pp. 11256-11261, 1997.

[28] S. Magnusson and T. Berg, "Extremely rapid endocytosis mediated by the mannose receptor of sinusoidal endothelial rat liver cells," Biochemical Journal, vol. 257, no. 3, pp. 651656, 1989.

[29] J. A. Summerfield, J. Vergalla, and E. A. Jones, "Modulation of a glycoprotein recognition system on rat hepatic endothelial cells by glucose and diabetes mellitus," The Journal of Clinical Investigation, vol. 69, no. 6, pp. 1337-1347, 1982.

[30] A. L. Hubbard and H. Stukenbrok, "An electron microscope autoradiographic study of the carbohydrate recognition systems in rat liver. II. Intracellular fates of the 125I-ligands," The Journal of Cell Biology, vol. 83, no. 1, pp. 65-81, 1979.

[31] L. East and C. M. Isacke, "The mannose receptor family," Biochimica et Biophysica Acta, vol. 1572, no. 2-3, pp. 364-386, 2002.

[32] T. Wileman, R. Boshans, and P. Stahl, "Uptake and transport of mannosylated ligands by alveolar macrophages. Studies on ATP-dependent receptor-ligand dissociation," Journal of Biological Chemistry, vol. 260, no. 12, pp. 7387-7393, 1985.

[33] R. Blomhoff, H. K. Blomhoff, H. Tolleshaug, T. B. Christensen, and T. Berg, "Uptake and degradation of bovine testes $\beta$ galactosidase by parenchymal and nonparenchymal rat liver cells," International Journal of Biochemistry, vol. 17, no. 12, pp. 1321-1328, 1985.

[34] A. L. Hubbard, G. Wilson, G. Ashwell, and H. Stukenbrok, "An electron microscope autoradiographic study of the carbohydrate recognition systems in rat liver. I. Distribution of 125Iligands among the liver cell types," The Journal of Cell Biology, vol. 83, no. 1, pp. 47-64, 1979.

[35] M. K. Bijsterbosch, W. Donker, H. van de Bilt, S. van Weely, T. J. C. van Berkel, and J. M. F. G. Aerts, "Quantitative analysis of the targeting of mannose-terminal glucocerebrosidase. Predominant uptake by liver endothelial cells," European Journal of Biochemistry, vol. 237, no. 2, pp. 344-349, 1996.

[36] L. Dini, A. Lentini, G. Mantile, M. Massimi, and L. C. Devirgiliis, "Receptor-mediated endocytosis of galactose and mannose exposing ligands: an electron microscopic study on adult and neonatal cultured rat hepatocytes," Biology of the Cell, vol. 74, no. 2, pp. 217-224, 1992.

[37] S. Magnusson and T. Berg, "Endocytosis of ricin by rat liver cells in vivo and in vitro is mainly mediated by mannose receptors on sinusoidal endothelial cells," Biochemical Journal, vol. 291, no. 3, pp. 749-755, 1993.

[38] L. Pelkmans and A. Helenius, "Insider information: what viruses tell us about endocytosis," Current Opinion in Cell Biology, vol. 15, no. 4, pp. 414-422, 2003.

[39] M. Marsh and A. Helenius, "Virus entry: open sesame," Cell, vol. 124, no. 4, pp. 729-740, 2006.

[40] I. Ellinger, H. Klapper, P. J. Courtoy, J.-P. Vaerman, and R. Fuchs, "Different temperature sensitivity of endosomes involved in transport to lysosomes and transcytosis in rat hepatocytes: analysis by free-flow electrophoresis," Electrophoresis, vol. 23, no. 13, pp. 2117-2129, 2002.

[41] M. Synnes, K. Prydz, T. Lovdal, A. Brech, and T. Berg, "Fluid phase endocytosis and galactosyl receptor-mediated endocytosis employ different early endosomes," Biochimica et Biophysica Acta, vol. 1421, no. 2, pp. 317-328, 1999.
[42] C. Rahner, B. Stieger, and L. Landmann, "Structure-function correlation of tight junctional impairment after intrahepatic and extrahepatic cholestasis in rat liver," Gastroenterology, vol. 110, no. 5, pp. 1564-1578, 1996.

[43] Y. Takakuwa, Y. Kokai, K.-I. Sasaki, et al., "Bile canalicular barrier function and expression of tight-junctional molecules in rat hepatocytes during common bile duct ligation," Cell and Tissue Research, vol. 307, no. 2, pp. 181-189, 2002.

[44] R. Kjeken, S. A. Mousavi, A. Brech, T. Gjoen, and T. Berg, "Fluid phase endocytosis of $\left[{ }^{125} \mathrm{I}\right]$ iodixanol in rat liver parenchymal, endothelial and Kupffer cells," Cell and Tissue Research, vol. 304, no. 2, pp. 221-230, 2001.

[45] L. K. Juvet, T. Berg, and T. Gjoen, "The expression of endosomal rab proteins correlates with endocytic rate in rat liver cells," Hepatology, vol. 25, no. 5, pp. 1204-1212, 1997.

[46] S. Sakisaka, M. Harada, K. Gondo, M. Yoshitake, and K. Tanikawa, "Tubulovesicular transport of horseradish peroxidase in isolated rat hepatocyte couplets: effects of low temperature, cytochalasin B and bile acids," Hepatology, vol. 20, no. 4, pp. 1015-1023, 1994.

[47] A. Esteller, "Physiology of bile secretion," World Journal of Gastroenterology, vol. 14, no. 37, pp. 5641-5649, 2008.

[48] M. Strazzabosco and L. Fabris, "Functional anatomy of normal bile ducts," The Anatomical Record, vol. 291, no. 6, pp. 653-660, 2008.

[49] Y. C. A. Keulemans, K. S. Mok, L. Th. de Wit, D. J. Gouma, and A. K. Groen, "Hepatic bile versus gallbladder bile: a comparison of protein and lipid concentration and composition in cholesterol gallstone patients," Hepatology, vol. 28 , no. 1, pp. 11-16, 1998.

[50] M. Ishii, B. Vroman, and N. F. LaRusso, "Fluid-phase endocytosis by intrahepatic bile duct epithelial cells isolated from normal rat liver," Journal of Histochemistry and Cytochemistry, vol. 38, no. 4, pp. 515-524, 1990.

[51] G. Yamada, N. Sawada, and M. Mori, "Evidence for fluidphase pinocytosis of extrahepatic bile duct cells isolated from normal rats in culture," Cell Structure and Function, vol. 17, no. 1, pp. 67-75, 1992.

[52] I. Stefaner, H. Klapper, E. Sztul, and R. Fuchs, "Free-flow electrophoretic analysis of endosome subpopulations of rat hepatocytes," Electrophoresis, vol. 18, no. 14, pp. 2516-2522, 1997.

[53] S. E. Autenrieth and I. B. Autenrieth, "Variable antigen uptake due to different expression of the macrophage mannose receptor by dendritic cells in various inbred mouse strains," Immunology, vol. 127, no. 4, pp. 523-529, 2009. 

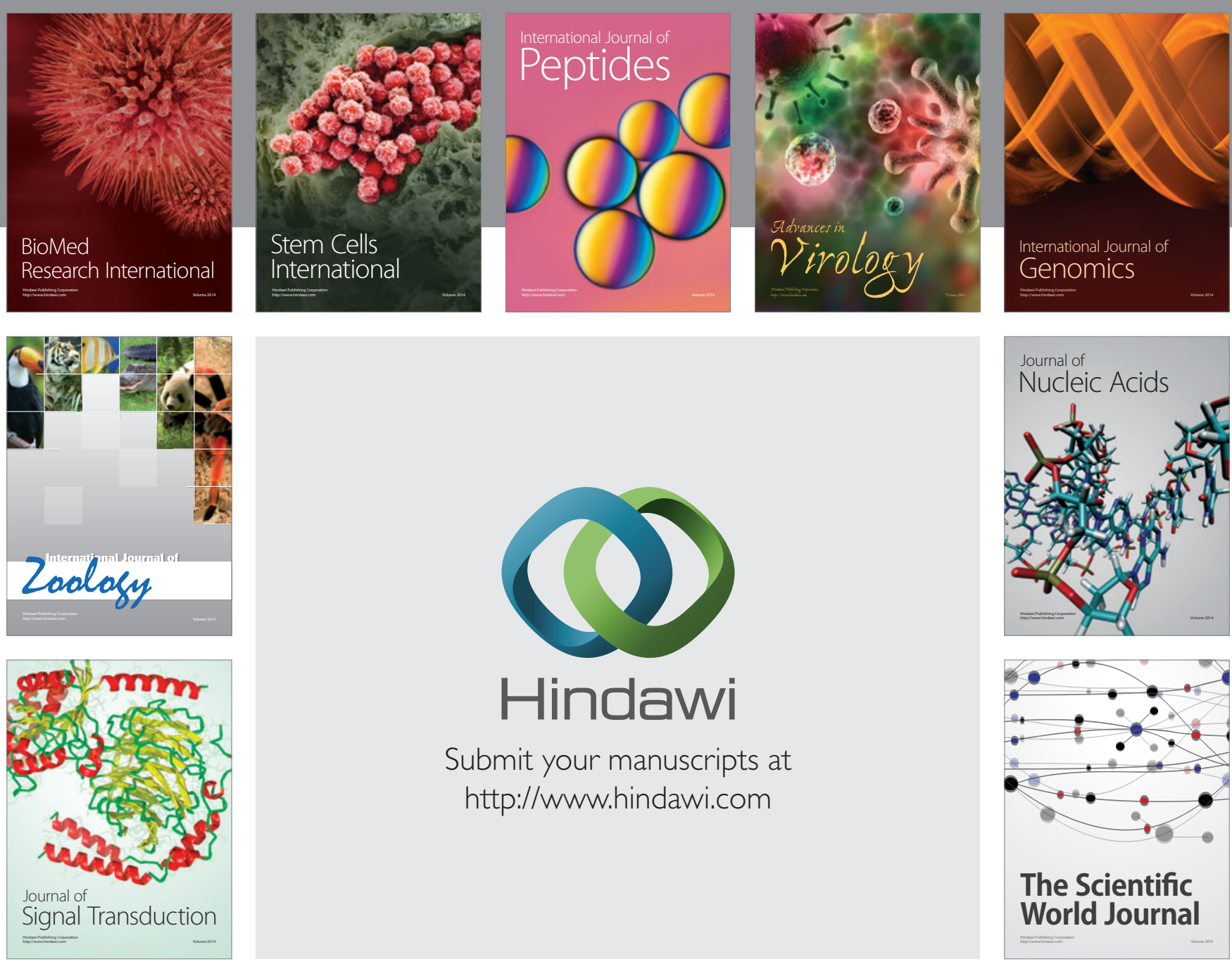

Submit your manuscripts at

http://www.hindawi.com
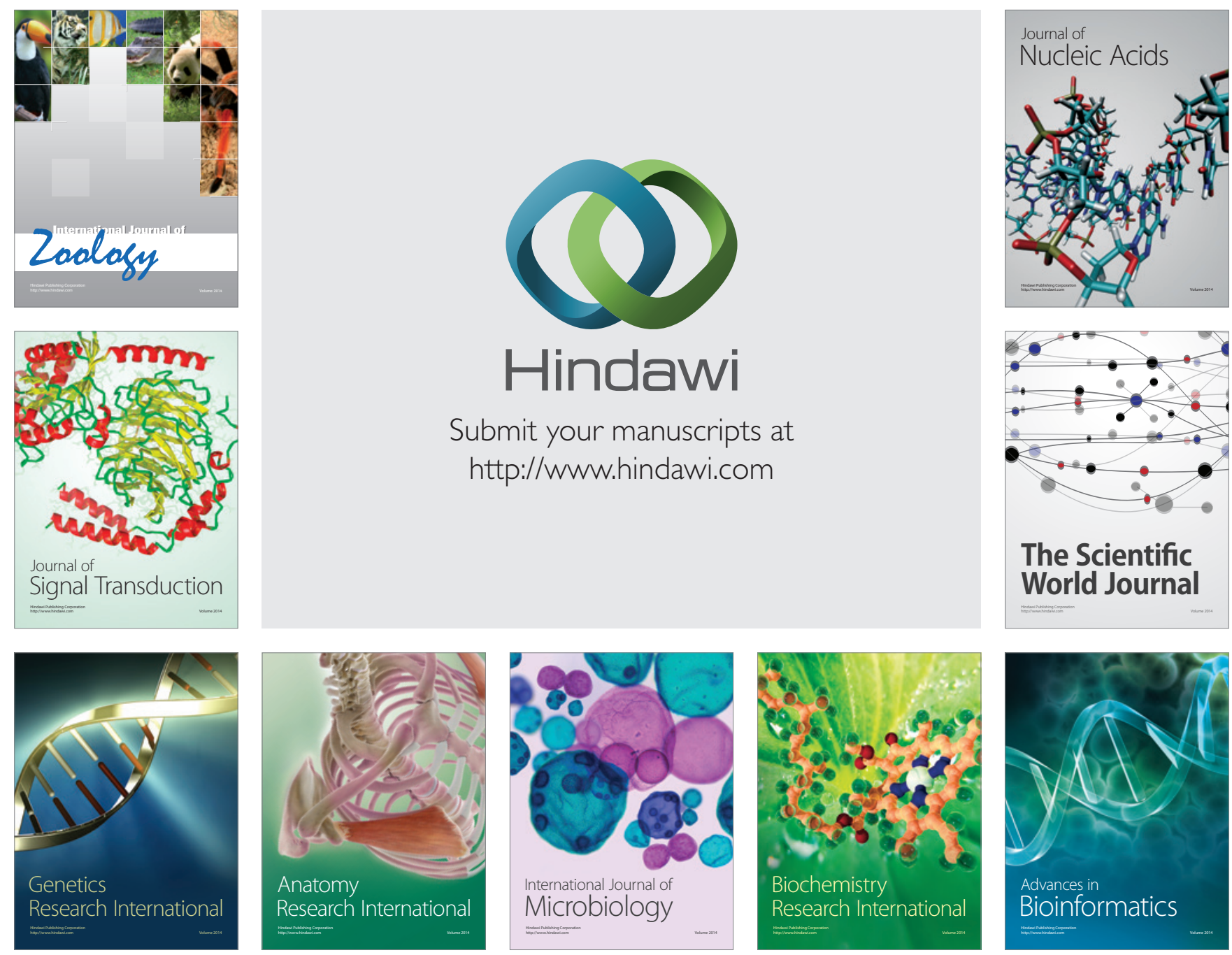

The Scientific World Journal
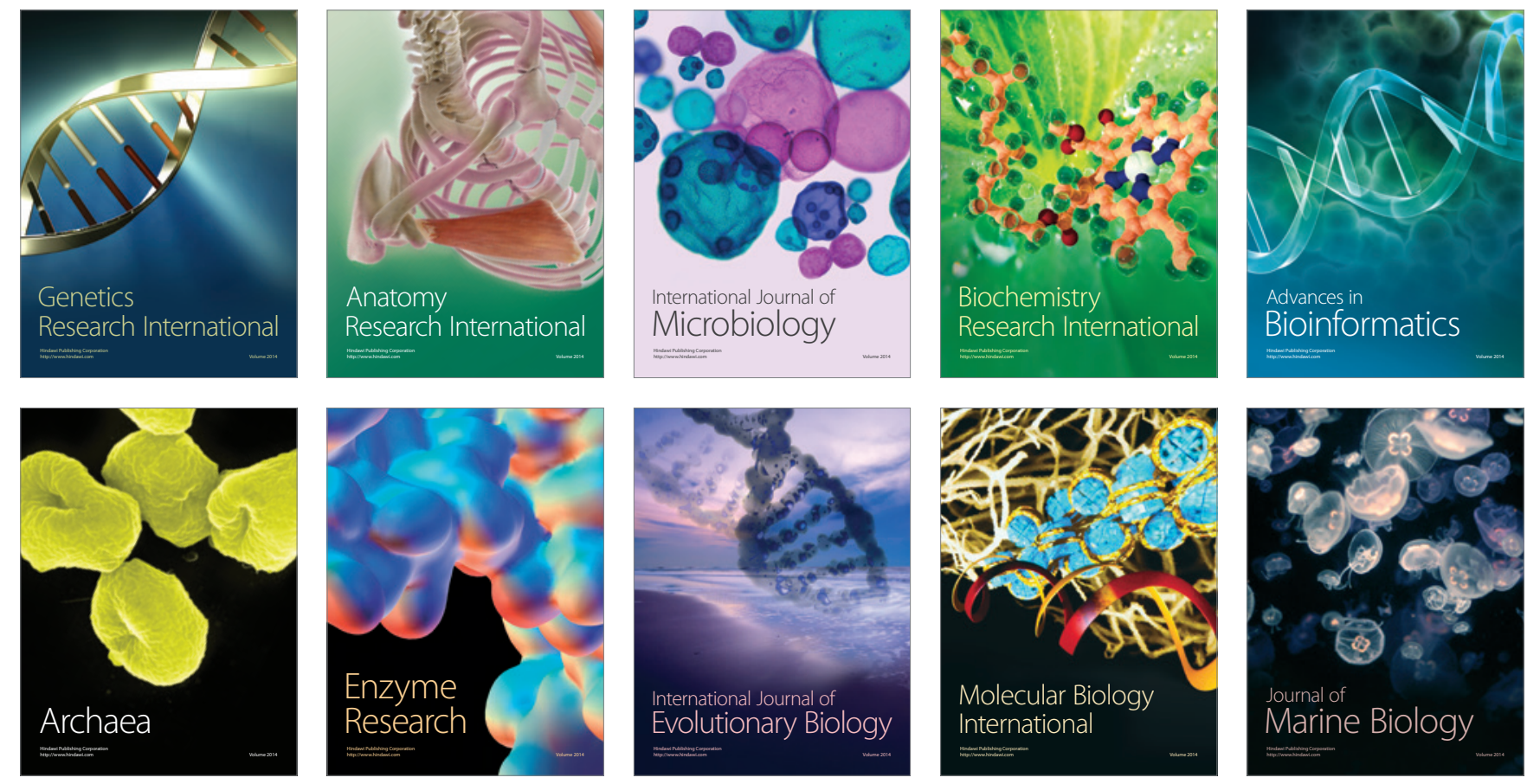